\title{
The Influence of Nitric Oxide on Perigeniculate GABAergic Cell Activity in the Anaesthetized Cat
}

\author{
C. Rivadulla, R. Rodríguez, S. Martínez-Conde, C. Acuña and J. Cudeiro
}

\begin{abstract}
We have tested the effect of iontophoretic application of the nitric oxide synthase inhibitor 1-nitroarginine on the activity of a population of 53 perigeniculate (PGN) cells, recorded extracellularly in the anaesthetized paralysed cat. In all cells tested with visual stimulation during 1-nitroarginine application $(n=15)$, the visually elicited responses were markedly reduced, on average by $63 \pm 15 \%$, and there was a reduction in spontaneous activity too. This effect was blocked by co-application of the substrate for nitric oxide synthase, 1-arginine, but not by the inactive d-isoform, although application of l-arginine alone was without effect. Pressure application of the nitric oxide donor $S$-nitroso- $N$ acetylpenicillamine (SNAP) elevated both visual responses and spontaneous discharge, an effect also seen with a second nitric oxide donor, sodium nitroprusside $(n=12)$. The nitric oxide synthase inhibitor l-nitroarginine was applied to a sub-population of seven cells and it selectively decreased NMDA mediated excitation (reduction $80 \%$ $14 \%$ ) with little or no effect on the excitation mediated by $\alpha$-amino-3-hydroxy-5-5-methyl-4-isoxazole-propionic acid (AMPA) or quisqualate (effects not statistically significant), and it had no effect $(n=7)$ on excitation mediated by the metabotropic agonist (1S,3R)-1-aminocyclopentane-1,3-dicarboxylic acid (ACPD). Furthermore, application of SNAP also increased the magnitude of excitatory responses mediated by NMDA receptors. On a different population of seven cells, application of the new NO donor diethylamine-nitric oxide (DEA-NO) enhanced the actions Of NMDA without an effect on responses to AMPA. These effects are qualitatively and quantitatively similar to those we have previously described for $\mathrm{X}$ and $\mathrm{Y}$ type cells in the dorsal lateral geniculate nucleus (dLGN), despite the known opposite effects of acetylcholine (ACh) application in the dLGN and PGN (ACh is co-localized with nitric oxide synthase at both sites). We propose that within the PGN nitric oxide acts to enhance transmission utilizing NMDA receptors selectively (thereby interacting with the globally inhibiting effect of ACh at this site) to enhance visual responses, reducing or removing the non-specific inhibitory drive from PGN to dLGN seen in the spindling activity of slow-wave sleep. These effects will act in concert with the facilitatory actions of both ACh and nitric oxide within the dLGN proper, and will thereby enhance the faithful transmission of visual information from retina to cortex.
\end{abstract}

Keywords: visual system; PGN; corticofugal; neuromodulation; parabrachial; spindle waves; sleep-wake cycle

\section{Introduction}

The perigeniculate nucleus (PGN), the visual component of the thalamic reticular nucleus, is a major extrinsic source of GABAergic innervation to the dorsal lateral geniculate nucleus (dLGN). The cells in the PGN have been shown to be immunoreactive for GABA, and they send their axons back into the thalamus, innervating both relay cells and local GABAergic interneurons (Fitzpatrick et al., 1984; Montero and Singer, 1984; Rinvik et al.,1987). The PGN receives visual input both from collaterals of dLGN relay cells (Ahlsen et al., 1978; Ferster and LeVay, 1978; Friedlander et al., 1981; Ahlsen and Lindstrom, 1982) and from collaterals of the dense descending corticofugal projection to the dLGN (Updyke, 1975, 1977; Boyapati and Henry,1984; Robson, 1984). This pattern of connectivity allows PGN cells to mediate the recurrent inhibition previously shown to operate on dLGN relay cells (Singer and Bedworth, 1973; Dubin and Cleland, 1977; Lindstrom, 1982). In addition, PGN cells receive a number of non-visual modulatory inputs, including cholinergic fibres from the parabrachial region of the brainstem, which also innervate the dLGN (Kimura et al., 1981; Ahlsen and Lo, 1982; DeLima and Singer, 1987; Steriade et al., 1987; Bickford et al., 1993; Funke and Eysel,1993).

Pharmacological investigations have demonstrated that acetyl- choline (ACh) markedly increases the discharge rate of dLGN relay cells, while PGN cells, like the intrinsic inhibitory interneurons within the dLGN, are inhibited (Ben Ari et al., 1976; Godfraind. 1978 Sillito et al., 1983; Eysel et al., 1986; McCormick and Prince, 1987; Francesconi et al., 1988). More recently, it has been shown that these cholinergic axons arising in the parabrachial region of the brainstem reach both dLGN and PGN and stain positively for nicotinamide adenine dinucleotide phosphate (NADPH)-diaphorase, a marker for the 
enzyme nitric oxide synthase (NOS) (Bickford et al., 1993). We have provided evidence that nitric oxide (NO) enhances the activity of dLGN relay cells activity by permitting full expression of NMDA evoked actions. This enhancement is apparently unrelated to the direct action of $\mathrm{ACh}$ in this nucleus (Cudeiro et al., 1994a, b; 1996). This raises the interesting possibility that activity in cholinergic fibres from the parabrachium may also act on PGN cells not only by the action of ACh itself but also via release of NO (co-localized with ACh; see Bickford et al., 1993), and in tum be involved in the GABA mediated control exerted by PGN, both within the PGN itself and on lateral geniculate cells. Here we have addressed this issue and concentrated mainly on two major questions; (i) Does NO influence the activity of cells in the PGN? (ii) If this is the case, does this action (like that we have previously shown in the dLGN) involve an action on NMDA mediated activity? A brief account of the findings has been published in abstract form (Rivadulla et al., 1995)

\section{Materials and methods}

\section{Animal preparation, recording and iontophoretic application of drugs}

Experiments were carried out on adult cats anesthetized with a mixture of $\mathrm{N}_{2} \mathrm{O}(70 \%), \mathrm{O}_{2}(30 \%)$ and halothane $(0.1-5 \%)$ and paralysed with gallarnine triethiodide $(10 \mathrm{mg} / \mathrm{kg} / \mathrm{h})$. Experimenta1 procedures for preparation and maintenance of cats and visual stimulation have been described previously (Cudeiro et al., 1996). Seven-barrelled micropipettes were used for recording single-unit activity and iontophoretic application of drugs in the PGN. Drug barrels contained a selection of the following solutions: $\mathrm{NaCl}$ (3 M for extracellular recording), L-arginine (L-Arg, $10 \mathrm{mM}, \mathrm{pH}$ 6.0), D-arginine (D-Arg, $10 \mathrm{mM}, \mathrm{pH}$ 6.0), $\mathrm{N}^{\mathrm{G}}$-nitro-L-arginine (L-NOArg, $10 \mathrm{mM}, \mathrm{pH}$ 6.0), sodium nitroprusside (SNP, applied by pressure ejection, $10 \mathrm{mM}$ ), S-nitroso-N-acetylpenicillamine (SNAP, applied by pressure ejection, $10 \mathrm{mM}$ ), diethylamine-nitric oxide complex sodium (DEA-NO, $10 \mathrm{mM}, \mathrm{pH}$ 8), NMDA (0.1 M, pH 8), D-2-amino5- phosphonova1erate (APV, $25 \mathrm{mM}, \mathrm{pH}$ 8), $\alpha$-amino-3-hydroxy-5-5- methyl-4-isoxazole-propionic acid (AMPA, $15 \mathrm{mM}, \mathrm{pH}$ 8), quisqualate (QUIS, $25 \mathrm{mM}, \mathrm{pH}$ 8.0), (1S,3R)-1-aminocyclopentane-1,3-dicarboxylic acid (ACPD, $50 \mathrm{mM}, \mathrm{pH} 8.0)$, ACh $(0.2 \mathrm{M}, \mathrm{pH} 4.5)$ or pontamine sky blue ( $2 \% \mathrm{w} / \mathrm{v}$, in $0.5 \mathrm{M}$ sodium acetate solution for histological reconstruction).

Pipettes tips were broken back to diameters ranging from 3 to $10 \mu \mathrm{m}$, and each drug barrel was subject to a constant retention current of 5-25 nA of appropriate polarity. Perigeniculate cells were identified by several criteria including anatomical localization, responses to visual stimulation, binocularity (Dubin and Cleland, 1977; Wrobel and Tarnecki, 1984; Xue et al., 1988; Uhlrich et al., 1991) and on the basis of their responses to iontophoretically applied $\mathrm{ACh}$, which produced a powerful suppression of cell discharge (see Fig. 1). The normally high spontaneous activity is immediately and markedly suppressed by application of $\mathrm{ACh}$, the opposite effect to that seen in LGN relay cells. In addition, histological verification of the anatomicallocation of a number of the recording sites was carried out by passing negative current (20-40 $\mu \mathrm{A})$ through an electrode barrel containing pontarnine sky blue for 15-20 min. After neutral red staining, the location of the blue spots marking the recording sites was determined

\section{Visual stimulation and experimental design}

Single unit data were collected and visual stimuli were produced under computer control (Visual Stimulation System, Cambridge Electronic Design, Cambridge, UK; for details see Sillito et al., 1993). Stimuli routinely consisted of sinusoidal drifting gratings with spatial and temporal frequencies qualitatively selected to produce the best response. The mean luminance $(\mathrm{L})$ was $14 \mathrm{~cd} / \mathrm{m}^{2}$ and stimulus contrast $\left[\left(\mathrm{L}_{\max }-\mathrm{L}_{\min }\right) /\left(\mathrm{L}_{\max }+\mathrm{L}_{\min }\right)\right]$ was held at $0.36-0.7$. For quantitative assessment of receptive field parameters a peristimulus histogram (PSTH) technique was used. Our basic experimental paradigm involved establishing control responses to a visual stimulus, which was then repeated during continuous iontophoretic application of an inhibitor of nitric oxide synthesis, either alone or in combination with DArg or L-Arg. Typically, responses were averaged over 10 stimulus presentations (each presentation involved 10 cycles of the sinusoidal grating) and were assessed from the accumulated counts in the binned and pooled data in the PSTHs. Where error bars are show these are +1 SEM. To examine the nature of the action of NOS inhibitors on excitatory responses evoked by exogenously applied NMDA we used pulsatile iontophoretic application of NMDA before and during continuous application of L-NOArg (again alone or in combination with D-Arg or L-Arg). The same protocol was used for the non-NMDA agonists AMPA, QUIS and ACPD. Pressure application of the NO donors SNP or SNAP alone or in combination with NMDA and iontophoretical ejection of DEA-NO were a1 so quantitatively examined in the same manner. The magnitude of the drug iontophoretic application current was selected on the basis 
of initial qualitative observations. In several experiments we included one barrel containing $0.9 \% \mathrm{NaCl}$, as a control to eliminate pressure mediated effects; volumes ejected ranged from 5 to $7 \mathrm{nl}$. It was clear that the increment in firing rate as a result of pressure ejection of both SNP and SNAP was not artefactually induced by the ejection technique, since similar pressure ejection of the saline (vehicle) had no effect on the spontaneous activity of the cells.
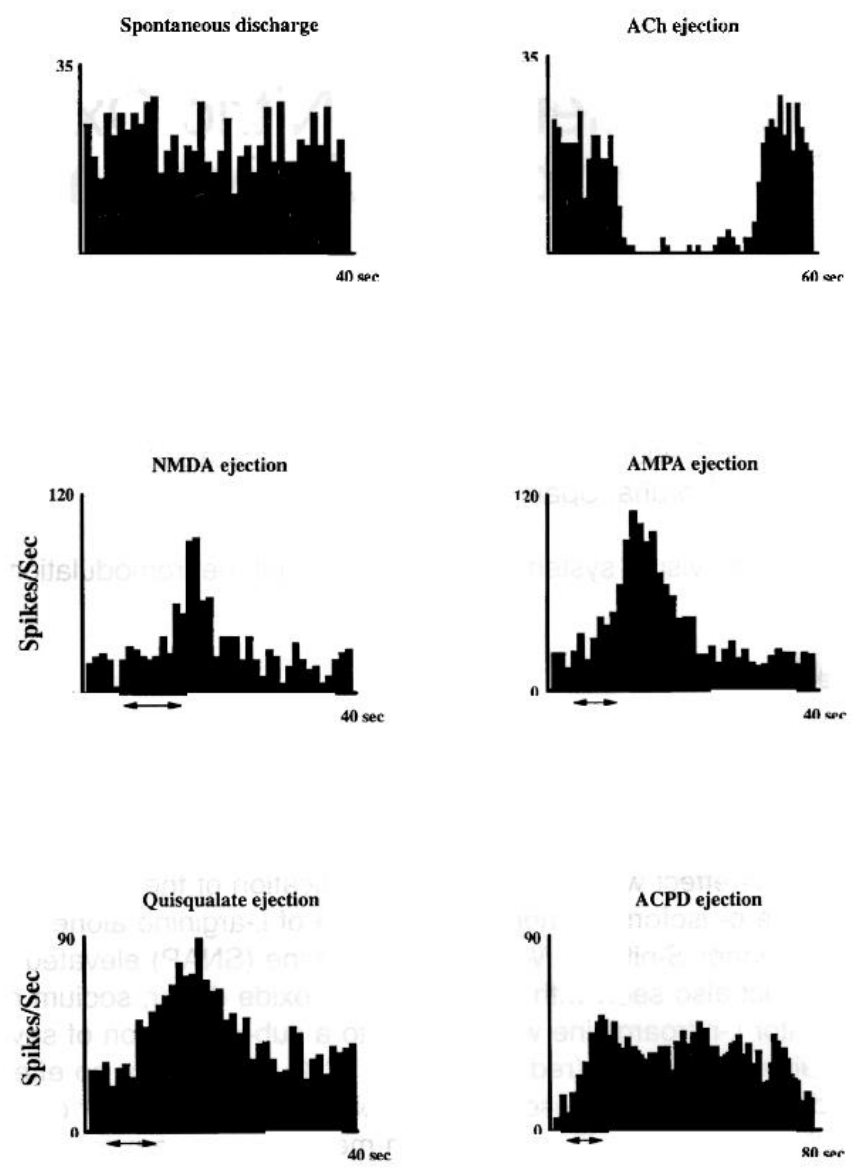

FIG. 1. Responses of single PGN cells, typical of those in this study. The top two PSTHs show the spontaneous activity of the cell (left) and the effect of iontophoretic application of ACh (right), which causes a rapid inhibition of spiking activity which continues for the duration of the application. The responses of the same cell to iontophoretic application of the excitatory amino acids NMDA, AMPA and QUIS are shown below. The effects of these compounds, unlike that of ACh, are similar in nature to those obtained during application to dLGN cells (where ACh is clearly excitatory). Finally, the excitatory response of a different cell obtained to application of the metabotropic agonist ACPD is shown in the bottom right PSTH. Arrowed horizontal1ines under the PSTHs indicate ejection times. Note that there are three different time scales in this figure.

\section{Results}

The data reported here derive from a total population of 53 cells recorded in PGN. All cells had receptive fields centred less than $13^{\circ}$ (degrees of visual angle) from the area centrales, and recording sites were located no more than $1000 \mu \mathrm{m}$ above the upper border of lamina A of the dLGN.

\section{Effect of application of NOS inhibitors on PGN cells activity}

All cells tested showed marked response reductions to visual stimulation during iontophoretic application of the NOS inhibitor L-NOArg $(n=15)$. This effect was blocked by concurrent ejection of LArg and unaltered by D-Arg, the biologically inactive isomer. This is shown in the PSTHs of Figure 2, which illustrates the response of a PGN cell to a drifting sinusoidal grating. In the upper row, the control 
response to visual stimulation alone is compared with those obtained during continuous iontophoretic ejection of L-NOArg, showing the temporal progression of the inhibitory effect. The visual response was clearly reduced by some $66 \%$ after 5 min of application. In the middle row, this cell was tested again after a recovery period, and the effect of simultaneous ejection of both L-NOArg and L-Arg during visual stimulation is illustrated. In this case neither the visual response nor spontaneous activity (horizontal dotted lines) was altered. Finally, after another recovery period, L-NOArg was applied together with DArg. Here again L-NOArg produced a marked reduction of the visual response, reinforcing the view that the suppressive effects of this compound are specific, and are the result of competitive inhibition of NOS. For this cell, application of L-Arg alone was without significant effect, the visual response being equal to the control level. On average, visual responses were reduced by $63 \pm 15 \%$ SEM $(\mathrm{P}<0.0001$, Wilcoxon test). There was a similar degree of suppression of background activity in all cases.

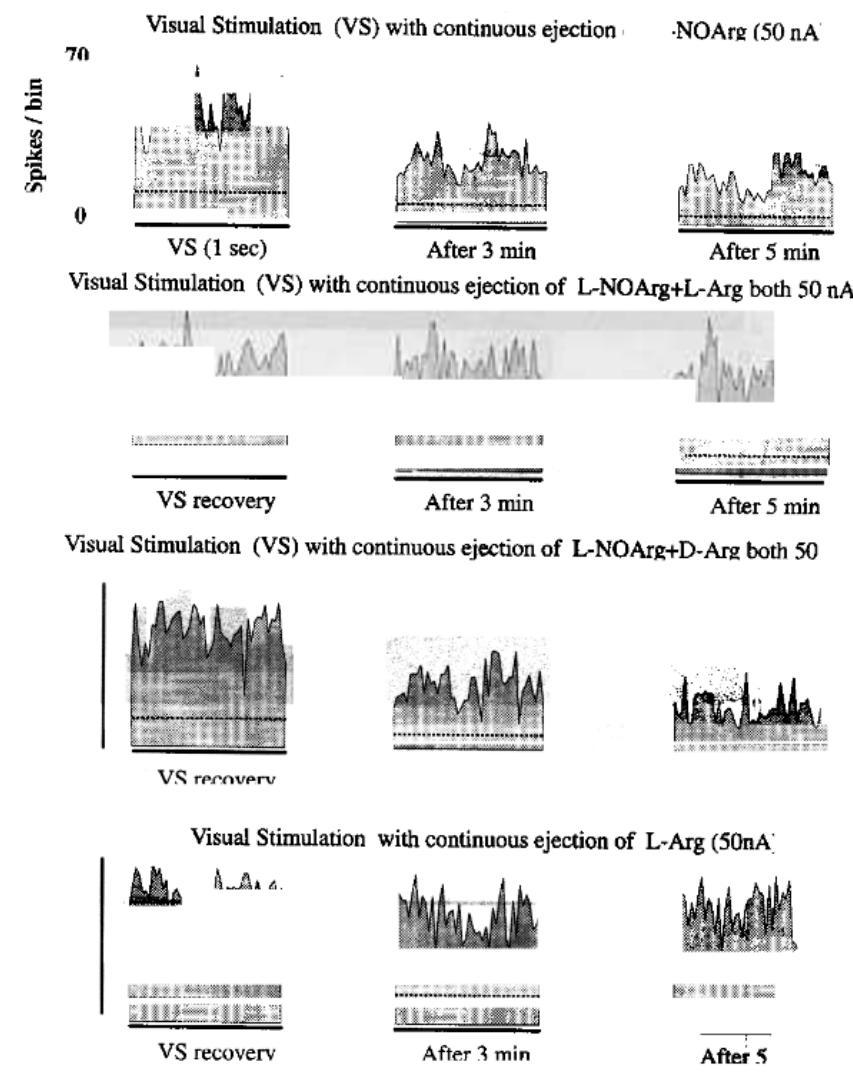

FIG. 2. The effects of L-NOArg, L-Arg and D-Arg on responses of a PGN cell to visual stimulation. The top row of PSTHs documents the effect of application of L-NOArg during presentation of a visual stimulus (a full-field sinusoidal drifting grating; spatial frequency $=0.4$ cycle/degree; temporal frequency $=1 \mathrm{cycle} / \mathrm{s})$. The control pre-drug response is on the left, and the middle PSTH shows activity during repeated presentation of the visual stimulus, 3 min after beginning the application of L-NOArg. The right PSTH shows a slightly increased inhibitory effect as the L-NOArg application is continued to 5 min. The second row of PSTHs again shows a control response, taken after recovery from the effect of L-NOArg application, and the middle and right PSTHs show no effect from application of L-NOArg, when it is applied in conjunction with L-Arg. The third row of PSTHs shows, from left to right, control and responses after 3 and $5 \mathrm{~min}$ of combined application of L-NOArg and D-Arg. Here again the inhibitory effects of L-NOArg are revealed. The lowest row of PSTHs documents the lack of effect of application of L-Arg alone; even after $5 \mathrm{~min}$ of application the visual responses are entirely unaffected. The dotted horizontal lines represent spontaneous/background activity. The bin width was $20 \mathrm{~ms}$ and the PSTH duration $1 \mathrm{~s}$; each PSTH shows the average of 10 trials.

\section{Effect of application of $\mathrm{NO}$ donors}

The effects of pressure ejection of the chemically unrelated NO donors SNAP and SNP on spontaneous activity are shown in Figure 3A. Application of either donor produced a clear increase in discharge rate. This type of effect $(\mathrm{P}<0.01$, Wilcoxon test) was found in all cell tested $(\mathrm{n}=12)$ and the spontaneous activity was enhanced by $\sim 130 \%$. As can be seen in the PSTHs, the effect of the application outlasted the period of ejection by many seconds. Furthermore, the NO donors (SNAP, in this case) were 
partially able to restore normal activity when they were applied concomitantly with L-NOArg (Fig. 3B). We also tested the application of SNAP on those cells studied with visual stimulation $(\mathrm{n}=8)$. A typical example is illustrated in Figure 4A. The control response is on the left and the PGN cell was stimulated with a sinusoidal drifting grating. On the right, the effect of SNAP application is shown. There is a significant enhancement of the visual response (from $40 \pm 2$ to $52 \pm 3$ spikes/s; $p<0.05$ Wilcoxon test, 10 presentations)
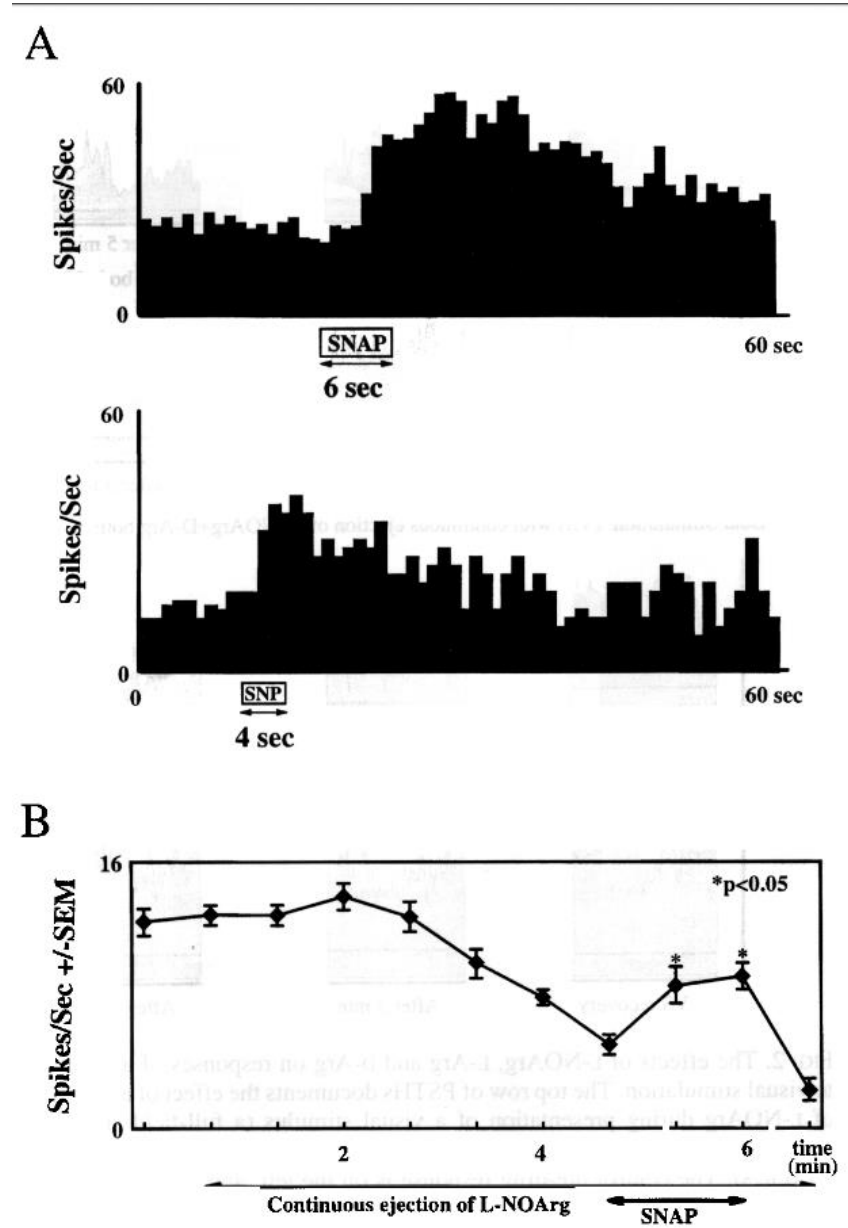

FIG. 3. (A) The effect of application of the NO donors SNAP and SNP on the spontaneous activity of PGN cells. In the upper PSTH a $6 \mathrm{~s}$ pressure ejection of SNAP caused an increase in firing in this cell after $\sim 4 \mathrm{~s}$, which peaked $\sim 6--10 \mathrm{~s}$ later (well after the end of drug ejection) and declined over the next 30-40 s. These values are typical of the population of 12 cells tested this way. The lower PSTH in (A) shows the effect of application of the NO donor SNP on the spontaneous activity of another PGN cell; a $4 \mathrm{~s}$ pressure ejection of SNP caused a rise in firing, more rapid in onset than that of SNAP. Each PSTH shows the average of five trials and the bin width was $1 \mathrm{~s}$. (B) Curve showing the temporal progression of the effect of NOS blockade on spontaneous activity of another PGN cell (mean \pm SEM). After 4 min of L-NOArg ejection, the spontaneous discharge declined by $\sim 61 \%$. Application of the NO donor SNAP significantly increased the spontaneous discharge, almost restoring the background activity to control levels. 
A

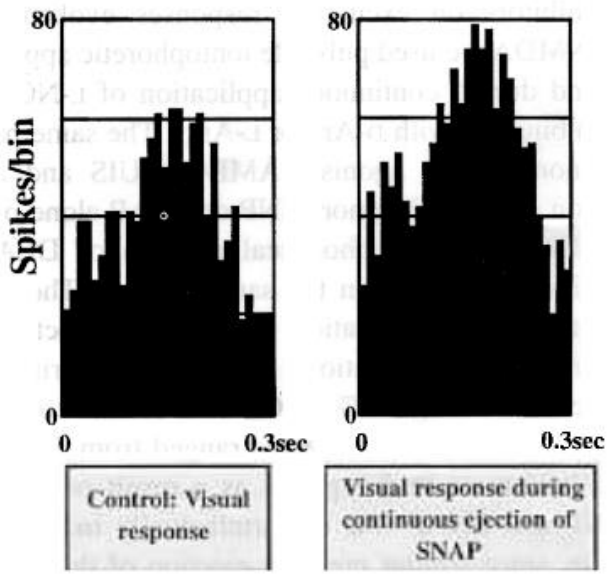

B

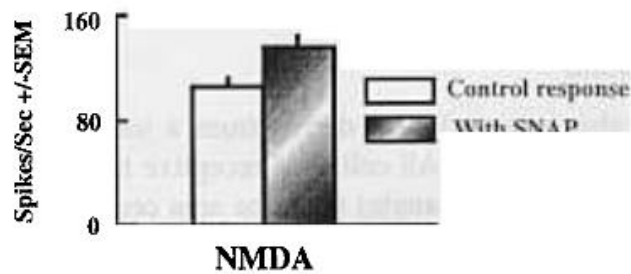

C

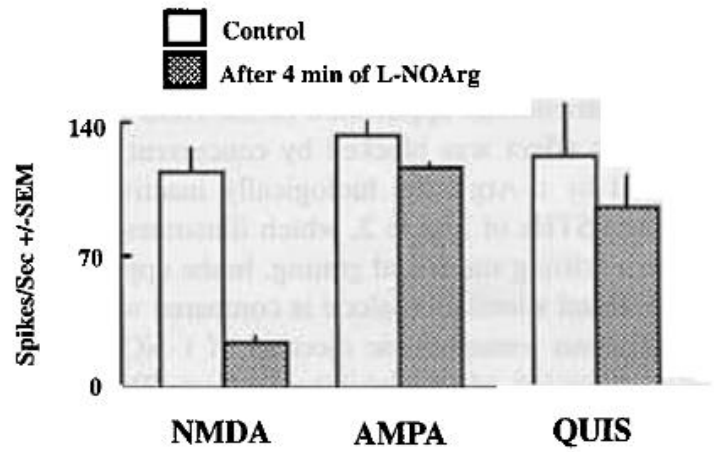

FIG. 4. (A) The effect of SNAP on the response of a PGN cell to visual stimulation. The left PSTH shows a control response to a drifting sinusoidal grating (spatia1 frequency $=0.1$ cycle/degree; temporal frequency $=3.3$ cycles/s; average of 10 presentations; bin width $=10 \mathrm{~ms})$. On the right the same visual stimulus was employed, but it was presented during continuous pressure ( 2 bar) application of SNAP. (B) Summary bar chart showing the effect of pressure application of the NO donor SNAP on excitatory responses of seven PGN cells to exogenously applied NMDA. (C) Bar chart comparing the mean excitatory responses of a population of seven PGN cells to NMDA, AMPA and QUIS alone (open bars) and in the presence of L-NOArg (80 nA, shaded bars, responses measured $4 \mathrm{~min}$ after L-NOArg onset). In B and C values are the population mean in spikes/s \pm 1 SEM, measured over a variable period of time starting and finishing when a significant change in the discharge of the cells was detected, according to the test of Sea1 et al. (1983) which determines the point of change using the maximum likelihood approach.

Effect of application of NOS inhibitors and donors on NMDA, AMPA, QUIS and ACPD evoked responses

In Figure 4B we illustrate the effect of application of the nitric oxide donor SNAP on NMDA evoked responses. Like its effect of visually driven responses (see Figure 4A), SNAP ejection significantly increased responsiveness to NMDA application $(28.6 \pm 6 \%, n=6, p<0.05$, Wilcoxon test). The effect of ejection of L-NOArg on NMDA, AMPA and QUIS evoked responses was tested on seven cells. Examples of these responses are shown in Figure 1; application of the NOS inhibitor resulted in a clear suppression of NMDA evoked excitation, while responses to AMPA and QUIS were largely unaffected. This is illustrated in Figure 4C where both effects are compared. Ejection of L-NOArg effectively reduced the responses to NMDA (left side) by $80.14 \%$ ( $\mathrm{P}<0.0001$, Wilcoxon test). Responses to AMPA and QUIS were much less reduced $(\sim 12.5 \%$, not significant). To investigate the effect of NOS inhibitors further, L-NOArg was ejected concomitantly with the specific metabotropic agonist ACPD. As shown in 
Figure 5, the excitatory respose evoked by ACPD application (Fig. 5A, left PSTH) was essentially unaffected by L- NOArg (right PSTH). Figure 5B shows the mean response obtained for a population of seven cells.
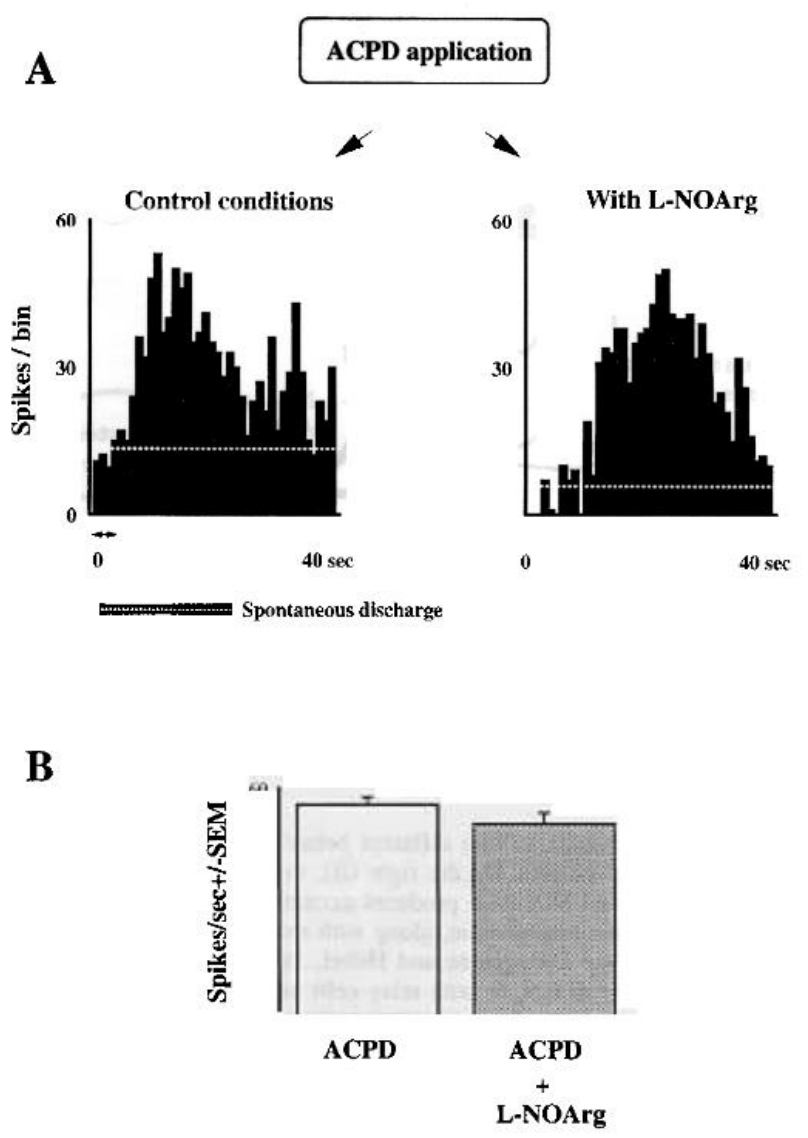

FIG. 5. (A) The PSTH on the left shows the excitatory response elicited by iontophoretically applied ACPD (80 nA, 4 s; see arrows) on a PGN cell. On the right, the effect of simultaneous ejection of ACPD and the NOS inhibitor L-NOArg (80 nA, continuous application) is illustrated. It is clear that the presence of the NOS inhibitor does not significantly affect the ACPD action. (B) Mean responses obtained for a population of seven cells. The bin width was $1 \mathrm{~s}$.

In a different group of seven cells, application of the new NO donor DEA-NO enhanced basal discharge, but not in the presence of the NMDA receptor antagonist APV (Fig. 6A). Furthermore, application of DEA-NO enhanced the excitatory responses to NMDA (Fig. 6A), but, significantly, did not alter the response to AMPA (Fig. 6B) (tested in the presence of continuous iontophoretic ejection of APV to avoid the effects of NMDA receptor mediated spontaneous activity shown in Fig. 6A). 


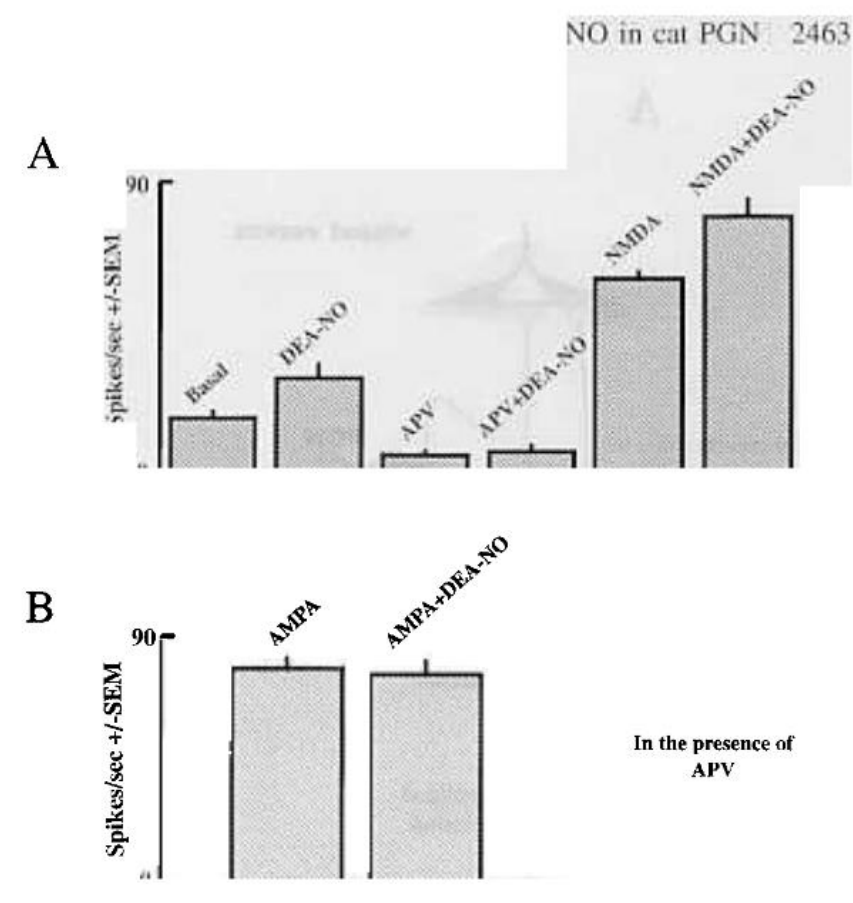

FIG. 6. (A) A bar chart showing the effect on basa1 discharge of the NO donor DEA.NO alone (column 2), APV alone (column 3 ) and the two together (column 4). Application of NMDA alone and in combination with DEA-NO is shown in the two columns on the right. (B) Comparison of the excitatory responses elicited by AMPA and AMPA + DEA-NO in the presence of continuous application of APV. The APV was applied with currents sufficient to suppress responses to NMDA selectively (data not shown). Each bar shows the mean for a population of seven cells (+SEM).

\section{Discussion}

These data show that the activity of PGN cells, like that of dLGN cells, can be markedly affected by iontophoretic application of the NOS inhibitor L-NOArg. That such an effect seems to be specifically due to inhibition of NO synthesis is supported by the following observations. (i) The inhibitory effect of LNOArg was antagonized by co-application of L-Arg, the biological substrate for the enzyme NOS. (ii) In a similar paradigm D-Arg, the biologically inactive isomer of arginine, was unable to restore normal activity. (iii) Application of the chemically unrelated NO donors SNP, SNAP or DEA-NO significantly increased both spontaneous activity and visually driven responses. It is known that the sole source of NOS in the dLGN/PGN complex is the cholinergic pathway from the parabrachium (Bickford et al., 1993) where NADPH-diaphorase, a marker for NOS has been shown to co-localize with ACh. However, the effects of ACh at the two sites are opposite, with enhancement of dLGN activity and suppression of PGN activity (Ben Ari et al., 1976; Godfraind, 1978; Sillito et al., 1983; Eysel et al., 1986; McCormick and Prince, 1987; Francesconi et al., 1988). Surprisingly, then, the data presented here show that blockade of NO synthesis in the PGN produces a potent and relatively selective reduction of NMDA evoked excitation, just as we have previously demonstrated for cells in the dLGN (Cudeiro et al., 1994b, 1996). A direct action of L-NOArg on NMDA receptors is unlikely, as L-NOArg has previously been shown neither to produce any effect on NMDA membrane currents nor affect $\left[{ }^{3} \mathrm{H}\right] \mathrm{MK}-801$ binding (Dawson et al., 1991). An interesting point arising from our results is the finding that L-Arg itself, while antagonizing the block of NO production, itself produces no further increase in firing. Again this mirrors our observations in the dLGN (Cudeiro et al. 1994a, b). In a previous study we excluded the possibility that this action of NOS blockade was NMDA selective only by virtue of the voltage selective nature of NMDA responses, by demonstrating that the effect of NOS blockade was still present when cells were hyperpolarized by exogenous application of GABA (Cudeiro et al., 1996). Although we have not repeated this experiment here, it seems unlikely that there should exist two separate mechanisms for the enhancement of NMDA responses at the level of the LGNI PGN complex. Furthermore, the inability of DEA-NO to enhance AMPA responses in the presence of APV suggests an NMDA specific action.

We propose that in normal function (or at least in the experimental conditions outlined here) available NOS, the enzyme producing NO, is fully active, being a rate limiting step in the control of NMDA 
mediated excitation. The similarity between these results and those obtained in the dLGN proper is at first surprising, given the opposite polarity of the effect of ACh application. Although this suggests a common mechanism of NO action operating throughout the dLGNI PGN complex in the cat, the difference in the actions of ACh (and by extension the actions of the parabrachial input) at these two sites must also be accounted for in any explanation for these effects. While the synaptic pharmacology of the PGN is as yet not fully characterized, it is clear that these cells respond in an excitatory fashion to the application of the excitatory amino-acids, NMDA, AMPA, QUIS and ACPD (e.g. see Fig. 1 and De Curtis et al., 1989). Furthermore, it has been demonstrated that the corticofugal input to the dLGN (and therefore to the PGN) utilizes an excitatory amino acid as neurotransmitter (Baughman and Gilbert, 1980; Montero and Wentho1d, 1989). Synaptic drive from the dLGN to the cortex a1so utilizes excitatory amino-acid receptors on postsynaptic cells in layer IV of cortex (Hagihara et al., 1988; Fox et al., 1989; Miller et al., 1989). Clearly, then, the collaterals of these two pathways are likely to use such an excitatory amino-acid as neurotransmitter at their synapses on PGN cells, although the postsynaptic receptors involved, at both dLGN and PGN leve1s, are stil a matter of debate. Interestingly, work by McConnick and colleagues (Bal et al., 1995) has suggested that EPSPs seen in PGN cells during spindle activity are due to activation of non-NMDA amino acid receptors (not NMDA receptor activation) arising from activity in the collaterals of dLGN relay cells which is, of course, most likely during slow wave sleep and other non-alert states when ascending cholinergic activity is diminished. Moreover, based on the prolonged EPSPs recorded in guinea pig dLGN relay cells after activation of corticothalamic fibres, it has been suggested that one component of the corticofugal input to the dLGN may utilize metabotropic excitatory amino acid receptors (McConnick and Von Krosigk, 1992). Our data comparing the effects of NOS inhibition on responses mediated by NMDA and those mediated by QUIS, which besides its action on ionotropic receptors can have agonistic actions on the majority of subtypes of metabotropic receptors (Pin and Duvoisin, 1995), and those mediated by the more specific metabotropic agonist ACPD, suggest that NO has no action at these sites, even if they are present on PGN cells.

We have previously hypothesized that the activity of the enzyme NOS, known to be $\mathrm{Ca}^{2+}$ dependent, may follow the level of activity in the cholinergic fibres of the parabrachial input, as terminal $\mathrm{Ca}^{2+}$ levels fluctuate (Cudeiro et al., 1996), utilizing the increased thalamic pool of arginine known to follow from sensory stimulation (Do et al., 1994). With this in mind it is tempting to speculate further that an increase in NO levels brought about by increasing parabrachial activity, during arousal or attentive periods, enhances the NMDA mediated transmission to the PGN via two different pathways: the activity of the relay cell collaterals and input from the visual cortex. Activity in the deep layers of the cortex, from which this input to the dLGN/PGN arises, is known to be diminished during sleep and increased during arousal (Livingstone and Hubel, 1981). Transition from slow wave sleep to the awake state is known to be associated with an increase in neurotransmitter release from many brainstem and hypothalarnic sites, including enhanced release of $\mathrm{ACh}$, noradrenaline, 5-hydroxytryptamine $(5 \mathrm{Ht})$ and histamine (for a review see Steriade and McCarley, 1990; McCormick, 1992). Thus a possible action of the parabrachial input would be to enhance cortical input from cells known to have visual receptive fields which are highly orientation and direction specific (Grieve and Sillito, 1995) selectively using NMDA receptors, at the expense of the relay cell feed-forward inhibition (LGN to PGN to LGN) driven by non-NMDA receptor activation, even though relay cell activity can be directly enhanced by both ACh and NO. (The importance of the relay cell collateral pathway is likely to be increased during spindle activity, in the relative absence of ACh and NO.) It is therefore interesting to note a recent study of the visual properties of PGN cells which showed that spontaneous activity was suppressed, while visual responsiveness was enhanced, during electrical stimulation of the parabrachium (Murphy et al., 1994). In this scenario, the parabrachial production of ACh would globally suppress PGN cell activity by means of muscarinic receptors, (perhaps enhancing visual activity with a transient nicotinic activation; see Lee and McCormick, 1995), and with release of NO would allow NMDA receptor activation to be enhanced relative to non-NMDA. We have illustrated these hypotheses in Figure 7.

In summary, the simplest explanation of the data we have presented here is to suggest that, as we have previously suggested for cells in the dLGN, the actions of NO serve to enhance visual responses of PGN cells, in particular those involving the activation of NMDA receptors. 
A

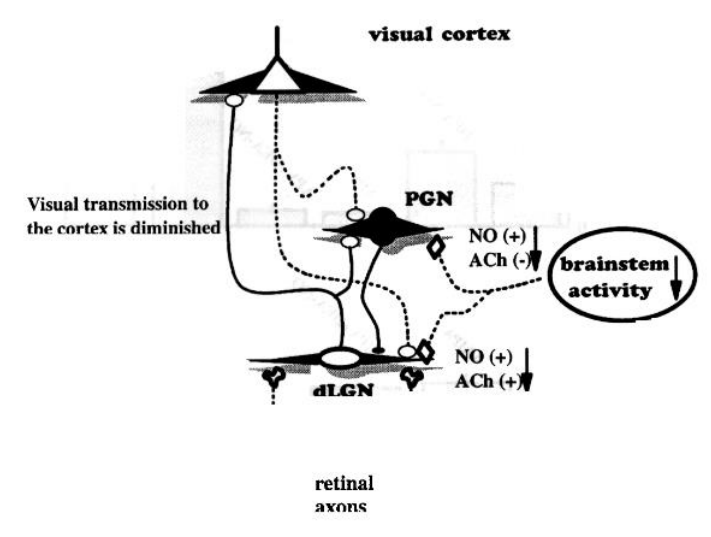

B

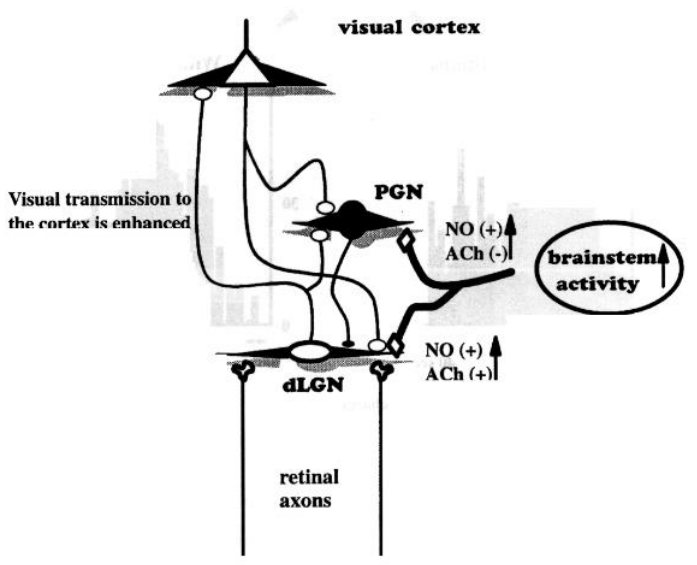

FIG. 7. Diagrammatic representation of the relative weights. of synaptic input to the dLGN/PGN complex in two different behavioural states. In A, retinal, parabrachial and cortical influences are minimized (dotted lines), enhancing the activity seen during spindles. On the right (B), in an attentive state, there is increased retinal drive, coupled with an increased drive from parabrachial cells [utilizing both ACh and NO; ACh produces excitatory effects on dLGN relay cells ( + ) while inhibiting PGN cells (-); crucially NO enhances excitatory activity on both sites]. This combination, along with modulatory influences on the cortex which directly enhance the visual responsiveness of cells projecting back to the LGN/PGN (see Livingstone and Hubel, 1981), enhances corticofugal output and transmission of this influence through the PGN to the dLGN (and of course directly to the dLGN, to both relay cells and inhibitory interneurons). Note that, although we allow equal power to the geniculo-cortical and geniculo-PGN paths in both states, the form of this activity (spindling in A and visually mediated in B) are markedly different. Clearly in this situation the PGN is involved in some visually driven inhibitory mechanism at the level of the LGN during attentive states; the nature of this influence is as yet incompletely understood but the relative timing of events may well prove to be of vital importance.

\title{
Acknowledgements
}

We are grateful to Dr K. L. Grieve for critical discussion and reading of the manuscript. This research was supported by Xunta de Galicia (Ayudas para Infraestructura), DGICYT (PB93-0347) and Vicerrectorado de Investigacion (Ayudas para Infraestructura), Universidad de La Coruña, Spain.

\author{
Abbreviations \\ ACh acetylcholine \\ ACPD ( 1 S.3R)-1-aminocyclopentane-1.3-dicarboxylic acid \\ AMPA a-arnino-3-hydroxy-5-5-methyl-4-isoxazole-propionic acid \\ APV D-2-arnino-5-phosphonovalerate \\ D-Arg D-arginine \\ L-Arg L-arginine \\ DEA-NO diethylamine-nitric oxide \\ dLGN dorsallateral geniculate nucleus \\ GABA y-arninobutyric acid \\ NADPH nicotinamide adenine dinllcleotide phosphate \\ L-NOArg L-N ${ }^{\mathrm{G}}$-nitro-L-arginine \\ NOS nitric oxide synthase \\ PGN perigeniculate nucleus \\ PSTH peristimulus time histograrn \\ QUIS quisqualate \\ SNAP S-nitroso-N-acetyl penicillamine \\ SNP sodium nitroprusside
}




\section{References}

Ahlsen, G., Ljndstrom, S. and Sybriska, E. (1978) Subcortical axon collaterals of princjpa1 cells in the lateral geniculate body of the cat. Brain Res., 156, 106-109.

Ahlsen, G. and Ljndstrom, S. (1982) Excitation of perigeniculate neurons via axon collaterals of principal cells. Brain Res., 236,477-481.

Ahlsen, G. and Lo, F.-S. (1982) Projection of brain stem neurons to the perigeniculate nucleus and the lateral geniculate nucleus in the cat. Brain Res., 238, 433-438.

Bal, T., von Krosjgk, M. and McCormick, D. A. (1995) Role of the ferret perigeniculate nucleus in the generation of synchronized oscillations in vitro. J. Physiol. (Lond.), 483, 665-685.

Baughman, R. W. and Gilbert, C. D. (1980) Aspartate and glutamate as possible neurotransmitters of cells in layer 6 of the visual cortex. Nature, 287, 848-850.

Ben Ari, Y., Dingledine, R., Kanazawa, I. and Kelly, J. S. (1976) Inhibitory effects of acetycholine on neurones in the feline nucleus reticularis tbalarni. J. Physiol. (Lond.), 261,647-671.

Bjckford, M. E., Günlük, A. E., Guido, W. and Sherman, S. M. (1993) Evidence that cholinergic axons from the parabrachial region of the brainstem are the exclusive source of nitric oxide in the latera1 geniculate nucleus of the cat. J. Comp. Neurol., 334,410-430.

Boyapati, J. and Henry, G. H. (1984) Corticofugal axons in the lateral geniculate nucleus of the cat. Exp. Brain Res., $53,335-340$.

Cudejro, J., Rivadulla, C., Rodriguez, R., Martinez-Conde, S., Acuña, C. and Alonso, J. M. (1994a) Modulatory influence of putative inhibitors of nitric oxide synthesis on visual processing in the cat lateral geniculate nucleus. J. Neurophysiol.. 71, 146-149.

Cudeiro, J., Grieve, K. L., Rivadulla, C., Rodriguez, R., Martinez-Conde, S. and Acuña, C. (1994b) The role of nitric oxide in the transformation of visual information within the dorsal lateral geniculate nucleus of the cat. Neurophannacology,33, 1413-1418.

Cudeiro, J., Rivadulla, C., Rodriguez, R., Martinez-Conde, S., Martinez, L., Grieve, K. L. and Acuña, C. (1996) Further observations on the role of nitric oxide in the feline lateral geniculate nucleus. Eur J. Neurosci., 88, 144152.

Dawson V. L., Dawson T. M., London E. D., Bredt D. S., Snyder S. H. (1991) Nitric oxide mediates glutamate neurotoxicity in primary cortical cultures. Proc. Natl Acad. Sci. USA, 88,6368-6371.

De Curtis, M., Spreafico, R. and Avanzini, G. (1989) Excitatory amino acids mediate responses elicited in vitro by stimulation of cortical afferents to reticularis thalarni neurons of the rat. Neuroscience, 33, 275-283.

De Lima, A. D. and Singer, W. (1987) The serotoninergic fibers in the dorsal lateral geniculate nucleus of the cat: distribution and synaptic connections demonstrated with immunocytochemistry. J. Comp. Neurol., 258,339-351.

Do, K.-Q., Binns, K. E. and Sa1t, T. E. (1994) Release of the nitric oxide precursor, arginine, from the thalamus upon sensory afferent stimulation, and its effect on tha1amic neurons in vivo. Neuroscience, 60,581-586.

Dubin, M. W. and Cleland, B. G. (1977) Organization of visual inputs to interneurons of the lateral geniculate nucleus of the cat. J. Neurophysiol., 40,410-427.

Eysel, U. T., Pape, H.-C. and Van Schayck, R. (1986) Excitatory and differentia1 disinhibitory actions of acetylcholine in the latera1 geniculate nucleus of the cat. J. Physiol. (Lond.), 370, 233-254.

Ferster, D. and Le Vay, S. (1978) The axonal arborizations of lateral geniculate neurons in the striate cortex of the cat. J. Comp. Neurol., 182, 923-944.

Fitzpatrick, D., Penny, G. R. and Schmechel, D. E. (1984) Glutamic acid decarboxylase immunocytoreactive neurons and terrninals in the lateral geniculate nucleus of the cat. J. Neurosci., 4, 1809-1829.

Fox, K., Sato, H. and Daw, N. (1989) The location and function of NMDA receptors in cat and kitten visual cortex. J. Neurosci., 9, 2443-2454.

Francesconi, W., Muller, C. M. and Singer, W. (1988) Cholinergic mechanisms in the reticular control of transmission in the cat lateral geniculate nucleus. J. Neurophysiol., 59, 1690-1718.

Friedlander, M. J., Lin, C. S., Standford, L. R. and Sherman, S. M. (1981) Morphology of functiona1ly identified neurons in lateral geniculate nucleus of the cat. J. Neurophysiol., 46, 80-129.

Funke, K. and Eysel, U. T. (1993) Modulatory effects of acetylcholine, serotonin and noradrenaline on the activity of cat perigeniculate neurons. Exp. Brain Res., 95, 409-420.

Godfraind, J. M. (1978) Acetylcholine and somatically evoked inhibition on perigeniculate neurones in the cat. BI: J. Phannacol., 63, 295-302.

Grieve, K. L. and Sillito, A. M. (1995) Differential properties of cells in the feline primary visual cortex providing the corticofugal feedback to the latera1 geniculate nucleus and visua1 claustrum. J. Neurosci., 15,4868-4874.

Hagihara, K., Tsumoto, H., Sato, H. and Hata, Y. (1988) Actions of excitatory amino acids antagonists on geniculocortical transmission in the cat's visual cortex. Exp. Brain Res., 69,407-416.

Kimura, H., McGeer, P. L., Peng, J. H. and McGeer, E. G. (1981) The central cholinergic system studied by choline acetyltransferase immuno- histochemistry in the cat. J. Comp. Neurol., 200, 151-201.

Lee, K. H. and McCormick, D. A. (1995) Acetylcholine excites GABAergic neurons of the ferret perigeniculate nucleus through nicotinic receptors. J. Neurophysiol., 73, 2123-2128.

Lindstrom, S. (1982) Synaptic organization of inhibitory pathways to principal cells in the lateral geniculate nucleus of the cat. Brain Res., 234, 447-453.

Livingstone, M. S. and Hubel, D. H. (1981) Effects of sleep and arousa1 on the processing of visual information in the cat. Nature, 291,554-561. 
McCormick, D. A. (1992) Neurotransmitter actions in the thalamus and cerebral cortex and their role in neuromodulation of thalamocortical activity. Prog. Neurobiol., 39, 337-388.

McCormick, D. A. and Prince, D. A. (1987) Actions of acetylcholine in the guinea-pig and cat medial and lateral geniculate nucleus, in vitro. J. Physiol. (Lond.), 392, 147-165.

McCormick, D. A. and von Krosigk, M. (1992) Corticothalarnic activation modulates thalarnic firing through glutamate .metabotropic' receptors. Proc. Natl Acad. Sci. USA, 89, 2774-2778.

Miller, K. D., Chapman, B. and Stryker, M. P. (1989) Visual responses in adult cat visual cortex depend on Nmethyl-D-aspartate receptors. Proc. NatlAcad. Sci. USA, 86,5183-5187.

Montero, V. M. and Singer, W. (1984) Ultrastructure and synaptic relations of neura1 elements containing glutamic acid descarboxylase (GAD) in the perigeniculate nucleus of the cat. Exp. Brain Res., 56, 115-125.

Montero, V. M. and Wenthold, R. J. (1989) Quantitative immunogold ana1ysis revea1s high glutamate levels in retinal and cortical synaptic terrninals in the lateral geniculate nucleus of the macaque. Neuroscience, 31, 639647.

Murphy, P, C., Uhlrich, D. J., Tarnarnaki, N. and Sherman, S. M. (1994) Brainstem modulation of the response properties of cells in the cat's perigeniculate nucleus. Vis. Neurosci., 11,781-791.

Pin, J.-P. and Duvoisin, R. (1995) The metabotropic glutamate receptors: structure and functions. Neurophannacology, 34, 1-26.

Rinvik, E., Otterson, O. P. and Storm-Mathisen, J. (1987) Gamma amino- butyrate-1ike immunoreactivity in the thalarnus of the cat. Neuroscience, 21,781-805.

Rivadulla, C., Rodriguez, R., Martinez-Conde, S., Acuña, C. and Cudeiro, J. (1995) Perigenicu1ate GABAergic cells of the cat are modulated by nitric oxide. Eur: J. Neurosci. Suppl., 8,32.17.

Robson, J. A. (1984) Reconstruction of corticogeniculate axons in the cat. J. Comp. Neurol., 225, 193-200.

Seal, J., Commenges, D., Salomon, R. and Bioulac, B. (1983) A statistical method for the estimation of neuronal response latency and its functional interpretation. Brain Res., 278, 382-386.

Sillito, A. M., Kemp, J. A. and Berardi, N. (1983) The cholinergic. influence on the function of the cat dorsal latera1 geniculate nucleus (dLGN). Brain Res., 280,299-307.

Sillito, A. M., Cudeiro, J. and Murphy, P. C. (1993) Orientation sensitive elements in the corticofugal influence on centre-surround interactions in the dorsal lateral geniculate nucleus. Exp. Brain Res., 93,6-16.

Singer, W, and Bedworth, N. (1973) Inhibitory interaction between X and y units in the cat latera1 geniculate nucleus. Brain Res., 49,291-307.

Steriade, M. and McCarley, R. W. (1990) Brainstem Control of Wakefulness and Sleep. Plenum Press, New York.

Steriade, M., Parent, A., Paré, D. and Smith, Y. (1987) Cholinergic and non- cholinergic neurons of cat basal fore brain project to reticular and mediodorsa1 thalamic nuclei. Brain Res., 408, 373-376.

Ulrich, D. J., Cucchiaro, J. B., Humphrey, A. L. and Sherman, S. M. (1991) Morphology and axonal projection patterns of individual neurons in the cat perigeniculate nucleus. J. Neurophysiol., 65, 1528;-1541.

Updyke, B. V. (1975) The patterns of projection of cortical areas 17, 18 and 19 onto the laminae of the dorsal lateral geniculate nucleus in the cat. J. Comp. Neurol., 163, 377-396.

Updyke, B. V. (1977) Topographic organization of the projection from cortical areas 17, 18 and 19 onto the thalamus, pretectum and superior colliculus. J. Comp. Neurol., 173, 81-122.

Wrobel, A. and Tamecki, R. (1984) Receptive fields of cat's non-relay lateral geniculate and perigeniculate neurons. Acta Neurobiol. Exp., 44, 289-299.

Xue, J. T., Camey, T., Ramoa, A. S. and Freeman, R. D. (1988) Binocular interaction in the perigeniculate nucleus of the cat. Exp. Brain Res., 69, 497-508. 